\title{
Natural mechanical degradation measurements in slow speed bearings
}

\author{
M. Elforjani ${ }^{*}$, D. Mba \\ School of Engineering, Cranfield University, Cranfield, Beds. MK43 0AL, UK. \\ *Email: elforjani@gmail.com
}

\section{Abstract}

Acoustic Emission (AE) technology applied to condition monitoring is gaining acceptance as a useful complimentary tool. This paper demonstrates the use of AE measurements to detect, monitor the growth and locate natural defect initiation and propagation in a conventional rolling element bearing. To undertake this task a special purpose test-rig was built to allow for accelerated natural degradation of a bearing race. It is concluded that crack initiation and its subsequent propagation is detectable with $\mathrm{AE}$ technology. The paper also investigates the source characterisation of $\mathrm{AE}$ signals associated with a defective bearing whilst in operation.

Keywords: Acoustic Emission, condition monitoring, natural degradation and thrust bearing.

\section{Introduction}

Acoustic Emission (AE) are transient elastic waves generated by the rapid release of energy from localized sources within a material [1]; typical frequency content of AE is between $100 \mathrm{kHz}$ to $1 \mathrm{MHz}$. A tremendous amount of work has been undertaken over the last 20-years in developing the application of the Acoustic Emission technology for bearing health monitoring [2]. The high sensitivity of AE in detecting the loss of mechanical integrity at early stages has become one of the significant advantages over the well-established vibration monitoring technique. Jamaludin et al. [3] presented the challenges faced with using the vibration technology to monitor the mechanical integrity of slow speed bearings (less than 60rpm) and suggested that the AE technology could overcome such difficulties. Sources of AE in rotating machinery include impacting, cyclic fatigue, friction, turbulence, etc. For instance, the interaction of surface asperities and impingement of the bearing rollers over a defect on an outer race will result in the generation of acoustic emission. These emissions propagate on the surface of the material as Rayleigh waves and are measured with an AE sensor. 
Other wave types associated with the propagation of AE include Lamb, Longitudinal and Shear waves.

To date most published work on the application of the AE to monitoring bearing mechanical integrity have been conducted on artificially or 'seeded' damage which are generally induced with an electrical discharge system, engraving machine or by introducing debris into the lubricant [2, 3, 4, 5, 6, 7]. However, Price et al. [8] showed the applicability of AE to monitor naturally generated scuffing and pitting defects in a four-ball lubricant test machine. To date the only published work of Yoshioka [9] could be considered the first that directly addressed identification of the onset of natural degradation in bearings with AE. It is worth noting that Yoshioka employed a bearing with only three rolling elements which is not representative of a typical operational bearing. Moreover, Yoshioka terminated AE tests once AE activity increased as such the propagation of identified sub-surface defects to surface defects was not monitored. This work builds further on the work of Yoshioka by monitoring not only the initiation of cracks, but also its propagation to spalls or surface defects on a conventional bearing with the complete set of rolling elements. The location of the $\mathrm{AE}$ source was also monitored throughout the test sequence in order to validate that the AE's generated throughout the test period can be eventually attributed to the surface defect noted at the end of the test

\section{Test-rig design and layout}

A specially designed test rig that encouraged the natural damage condition of a test bearing was employed. To accelerate natural crack initiation a combination of a thrust ball bearing and a thrust roller bearing was employed. One race of thrust ball bearing (SKF 51210) was replaced with a flat race taken from thrust roller bearing (SKF $81210 \mathrm{TN}$ ) of the same size, as shown in figure 1. As a consequence, this arrangement caused higher contact pressure on a flat track relative to the grooved track due to the reduced contact area between the ball elements and the flat race. 


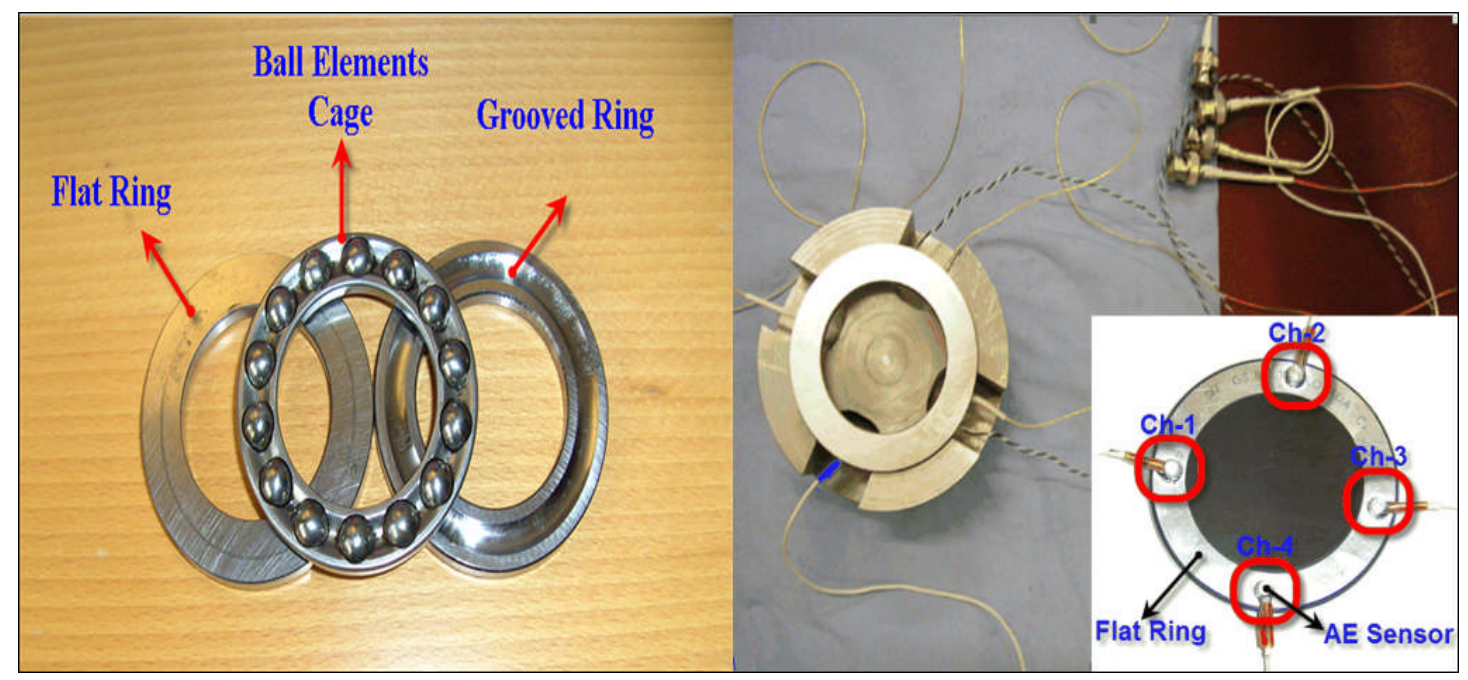

Figure 1 Test bearing arrangement

For this study, bearing run to failure tests were performed under natural damage conditions. A specifically designed test-rig, as shown in figure 2, was employed for this investigation. It consisted of a hydraulic loading device, a geared electrical motor (MOTOVARIO-Type HA52 B3-B6-B7 j20, 46-Lubricated: AGIP), a coupling and a supporting structure. The test bearing was placed between the fixed thrust loading shaft and the rotating disk which housed the grooved race. The flat race was fitted onto the loading shaft in a specifically designed housing. This housing was constructed to allow for placement of AE sensors and thermocouples directly onto the race. The thrust shaft was driven by a hydraulic cylinder (Hi-Force HYDRAULICSMODEL No: HP110-HAND PUMP-SINGLE SPEED-WORKING PRESSURE: 700 BAR) which moved forward to load the bearing and backwards for periodic inspections of the test bearing face. The rotating disk was driven by a shaft attached to a geared motor with an output speed of 72rpm. A thrust bearing (SKF $81214 \mathrm{TN}$ ) was placed between the coupling and the test bearing and a flexible coupling was employed between the shaft and the geared motor. 


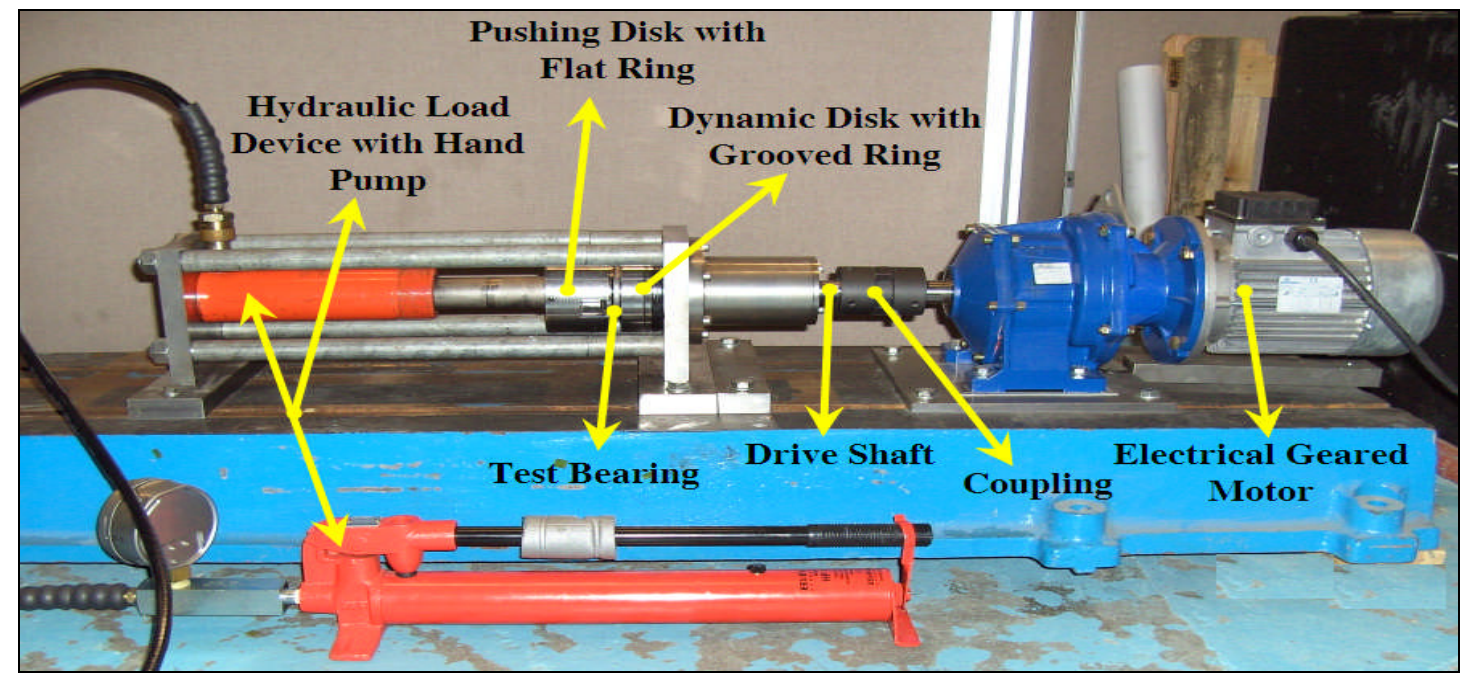

Figure 2 Test-rig layout

\section{Instrumentations}

A schematic of the data acquisition process is detailed in figure 3. The AE acquisition system employed commercially available piezoelectric sensors (Physical Acoustic Corporation type "PICO") with an operating range of $200-750 \mathrm{kHz}$ at temperatures ranging from -65 to $177^{\circ} \mathrm{C}$. Four $\mathrm{AE}$ sensors, together with two thermocouples (RoHS-Type: J x 1M 455-4371) were attached to the back of the flat raceway, see figure 1. The acoustic sensors were connected to a data acquisition system through a preamplifier (40 dB gain), see figures 3 .

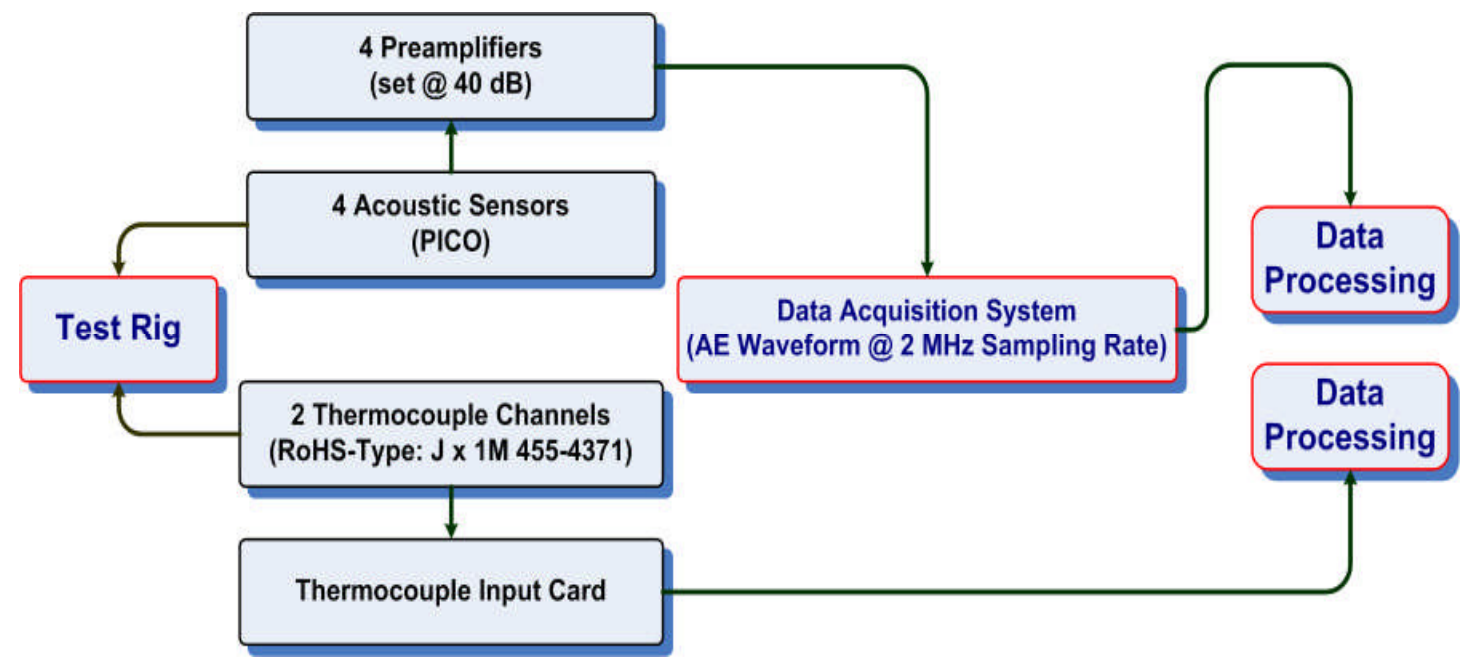

Figure 3 Schematic of the data acquisition systems 
The acquisition system was continuously set to acquire AE absolute energy (Joules) over a time constant of $10 \mathrm{~ms}$ at a sampling rate of $100 \mathrm{~Hz}$. The absolute energy is a measure of the true energy and is derived from the integral of the squared voltage signal divided by the reference resistance $(10 \mathrm{k}-\mathrm{ohms})$ over the duration of the $\mathrm{AE}$ signal. In addition to continuous recording of AE absolute energy (Atto-Joules or $10^{-18}$ Joules, AE waveforms were periodically acquired at a sampling rate of $2 \mathrm{MHz}$. In all cases, AE measurements were taken simultaneously from all four AE sensors.

Under normal conditions of load, rotational speed and good alignment, surface damage begins with small cracks, located between the surface of the flat track and the rolling elements, which gradually propagate to the surface generating detectable AE signals. The procedure employed to determine the test duration to the onset of surface fatigue has been previously described by Elforjani et al. [10] and involved the Hertizan theory for determining surface stresses and deformations [11], Thomas and Hoersh theory for sub-surface stress [11], and, the Lundberg and Palmgren theory for fatigue evaluation [12].

\section{Experimental Results Observations and Discussions}

\subsection{AE source location}

The capability of AE to determine source locations of signals emanating in real time from materials under load is one of the significant advantages AE offers over other non-destructive test (NDT) technologies. In application the AE signals travelling through the medium are attenuated and arrive at different sensors with a time delay. This delay can be attributed to the distance between the source (defect) and AE sensors, and, with knowledge of the signal velocity the location of the AE source can be identified. For this particular investigation efforts were made to identify the defect location (AE source location) in real-time. This was accomplished by identifying the wave velocity on the ring experimentally. At a threshold of $52 \mathrm{~dB}$ and with known distances between the AE sensors, the velocity of the AE waveform under such conditions was experimentally determined at 4,000 m/sec. Interestingly, the dominant frequency content of AE's recorded was approximately $300 \mathrm{kHz}$ and the wave velocity of $4,000 \mathrm{~m} / \mathrm{sec}$ corresponds to the symmetric zeroth lamb wave mode (So) for steel at 
$1.8 \mathrm{mmMHz}(0.3 \mathrm{MHz} \times 6 \mathrm{~mm}$ thk $)$ The propagation velocity $(4,000 \mathrm{~m} / \mathrm{sec})$ was used for all source location investigations and prior to the onset of testing several HsuNielsen sources were made at various positions on the surface to establish the accuracy at this velocity and specific threshold level. Results were within $4 \%$ of the exact geometric location of the Hsu-Nielsen sources. Figure 4 shows the source location layout used which essentially 'unwrapped' the bearing race for linear location.

The location plots show cumulative energy over the test simulation. It is worth mentioning that only $\mathrm{AE}$ events above a threshold of $52 \mathrm{~dB}$ contribute to the source location. Whenever the threshold is exceeded, the location of the source is computed and identified. The AE energy is assigned to the geometric position (source); this is a cumulative process and as such a fixed source will have the largest contributory energy in a cumulative plot.

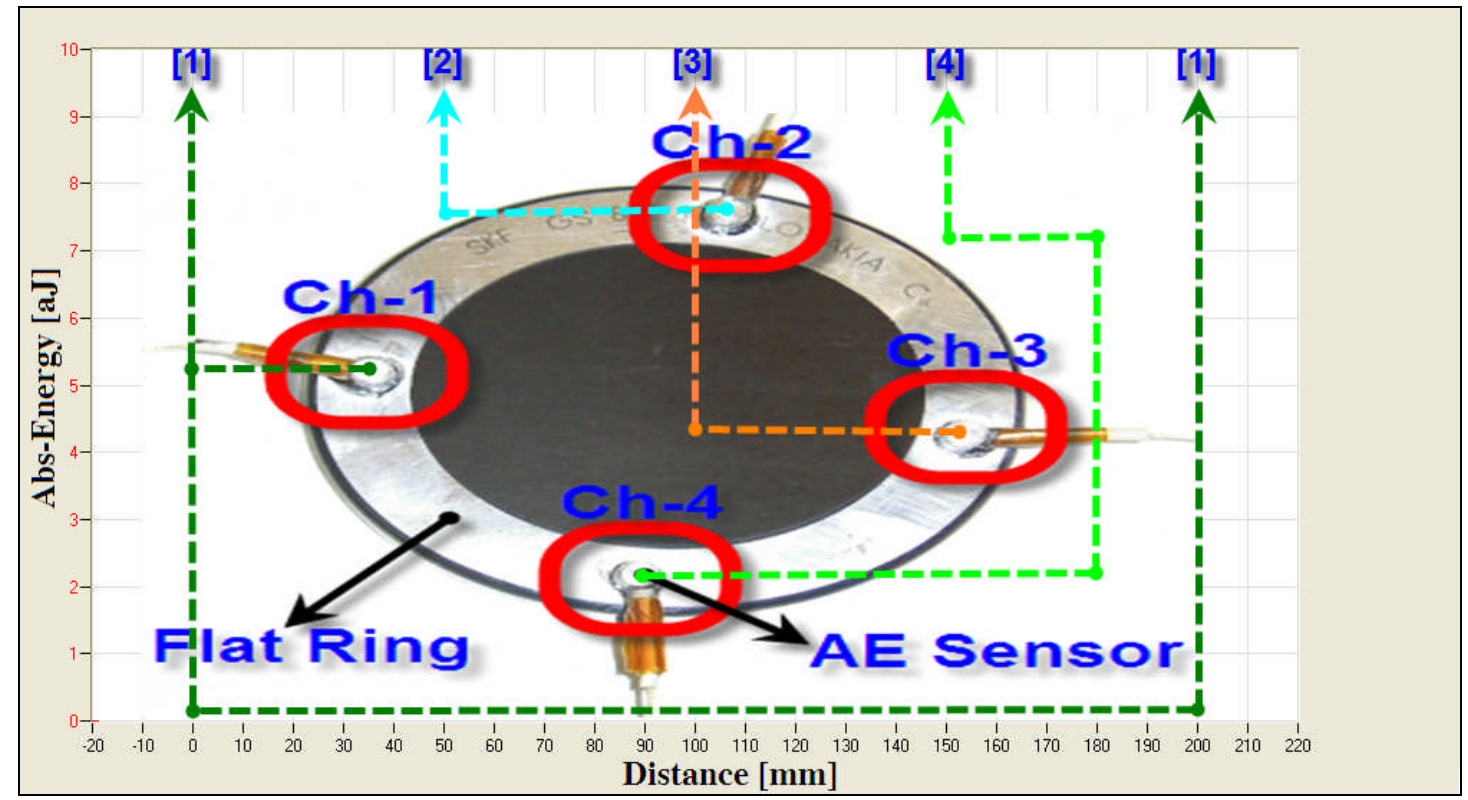

Figure 4 Source location layout for linear detection

\section{$5.2 \quad$ Bearing Tests}

For this particular paper three experimental cases are presented that reflect the general observations associated with over a dozen experimental tests at loads ranging from 20, 35 and $50 \mathrm{kN}$. Case I represents observations noted at a load condition of 50kN 
whilst Case II and Case III present results for a test load of $35 \mathrm{kN}$ and $20 \mathrm{kN}$ respectively.

\subsubsection{Case I}

Observations of AE energy monitored continuously over 16-hrs (hours) of bearing operation are presented in figure 5 . An axial force of $50 \mathrm{kN}$ was applied on the test bearing. During the first hour of the test, an increase in AE activity levels and temperature was noted. This was attributed to the 'run-in' phase, as after this period (1-hr) all measured AE parameters and temperature remained constant for another 9hrs, see figure 4. It was observed that at approximately 10-hrs into the test AE started to increase steadily until the test was terminated (16-hrs). It is worth mentioning that the bearing was lubricated during the testing with Castrol, Moly Grease (650-EL). Following run-in (0- to $1-\mathrm{hr})$ the bearing temperature stabilized at $35^{\circ} \mathrm{C}$ and after $16-$ hrs operation a maximum temperature of $40^{\circ} \mathrm{C}$ was recorded, see figure $5 . \mathrm{AE}$ waveforms, recorded during the test, clearly showed AE transient events after 10hours, and by the termination of the test, $\mathrm{AE}$ waveforms showed a periodicity of $\mathrm{AE}$ transient bursts at a frequency equivalent to $9 \mathrm{~Hz}$, see figure 6 . At the end of the test (16-hrs) visible surface damage was observed with a circumferential length of $20 \mathrm{~mm}$ see figure 7; a damage had occurred in the region close to ch-1 AE sensor. The relevance of this will be evident later.

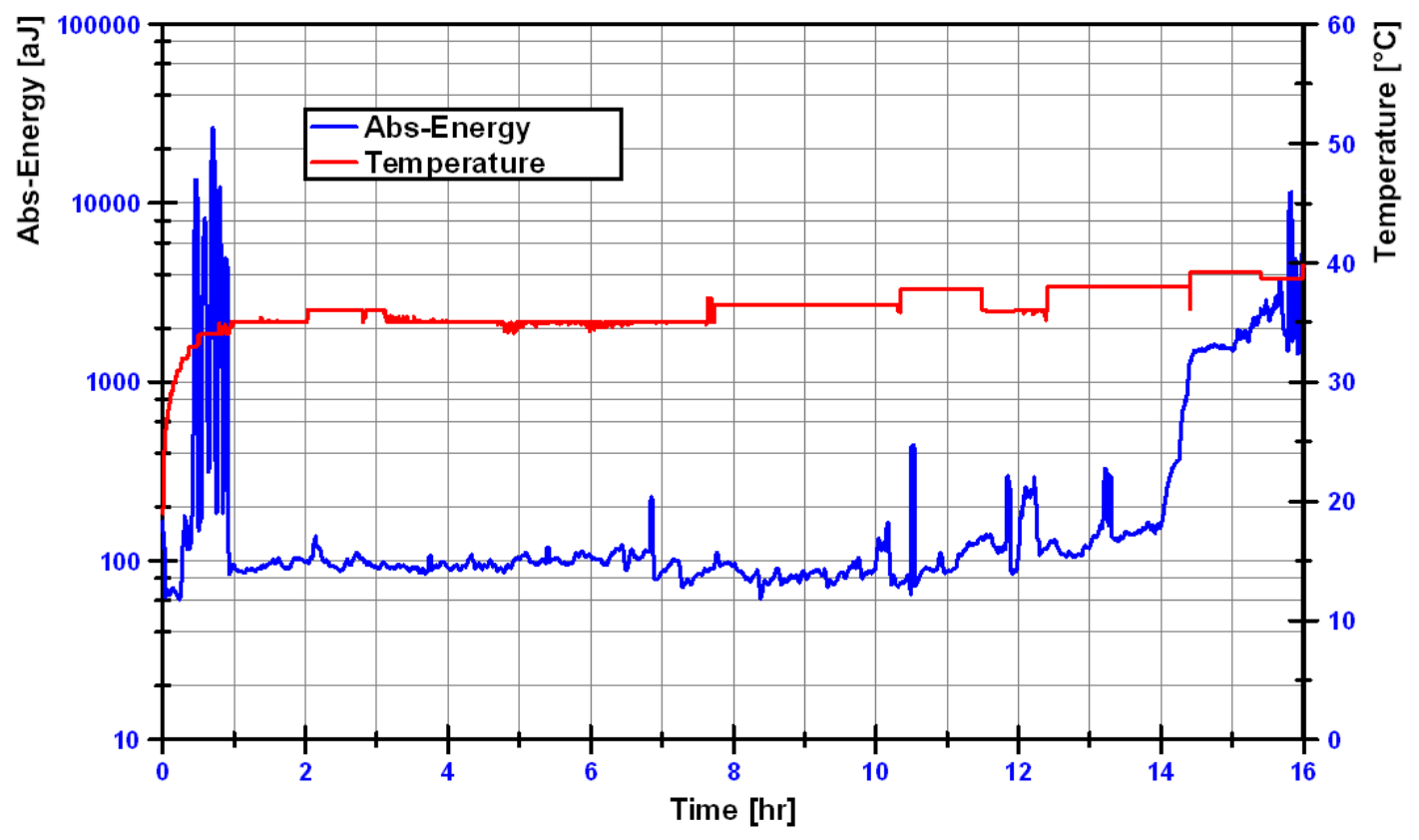

Figure 5 Test conditions run until visually observable surface damage 

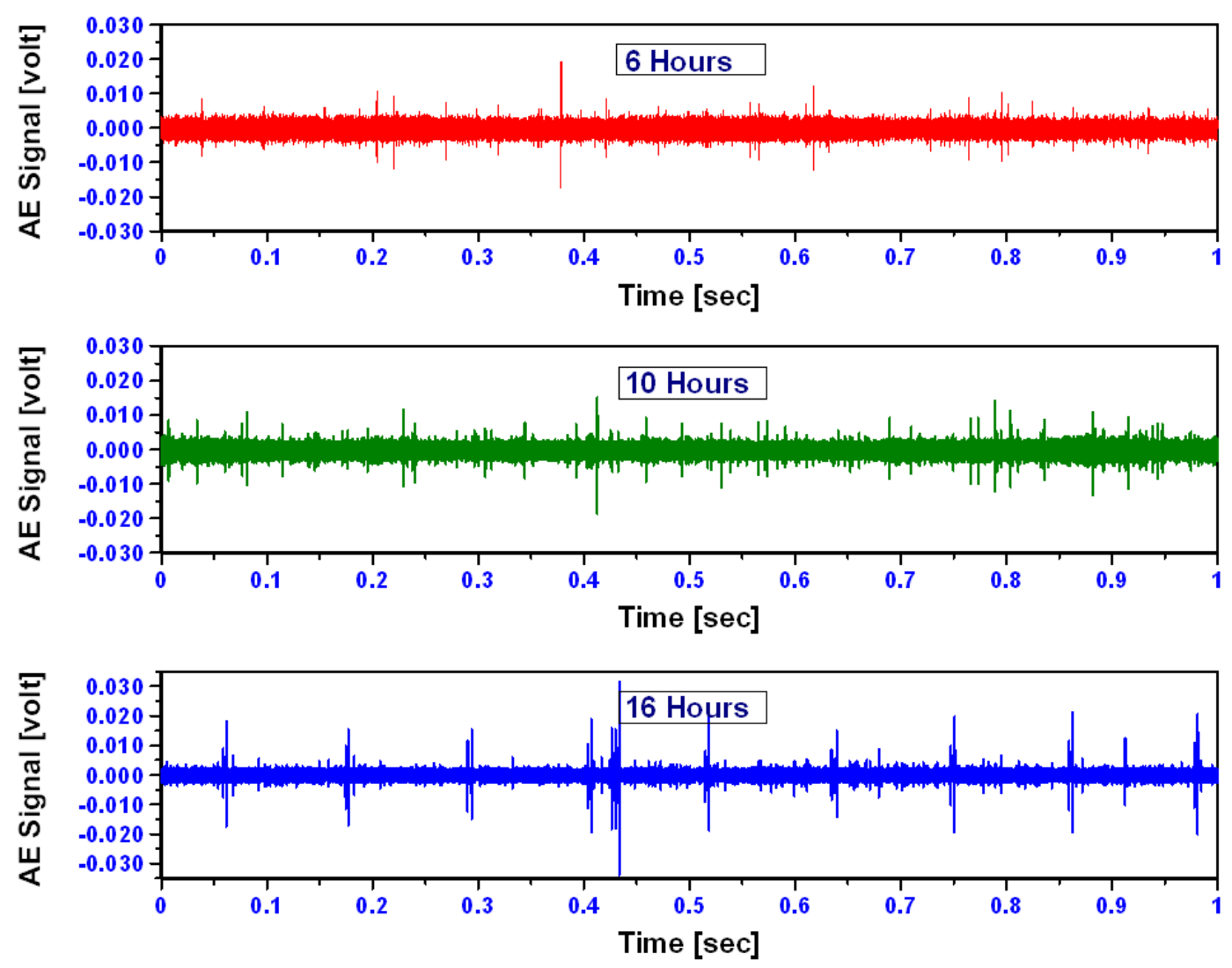

Figure 6 Typical AE waveforms during test case-I

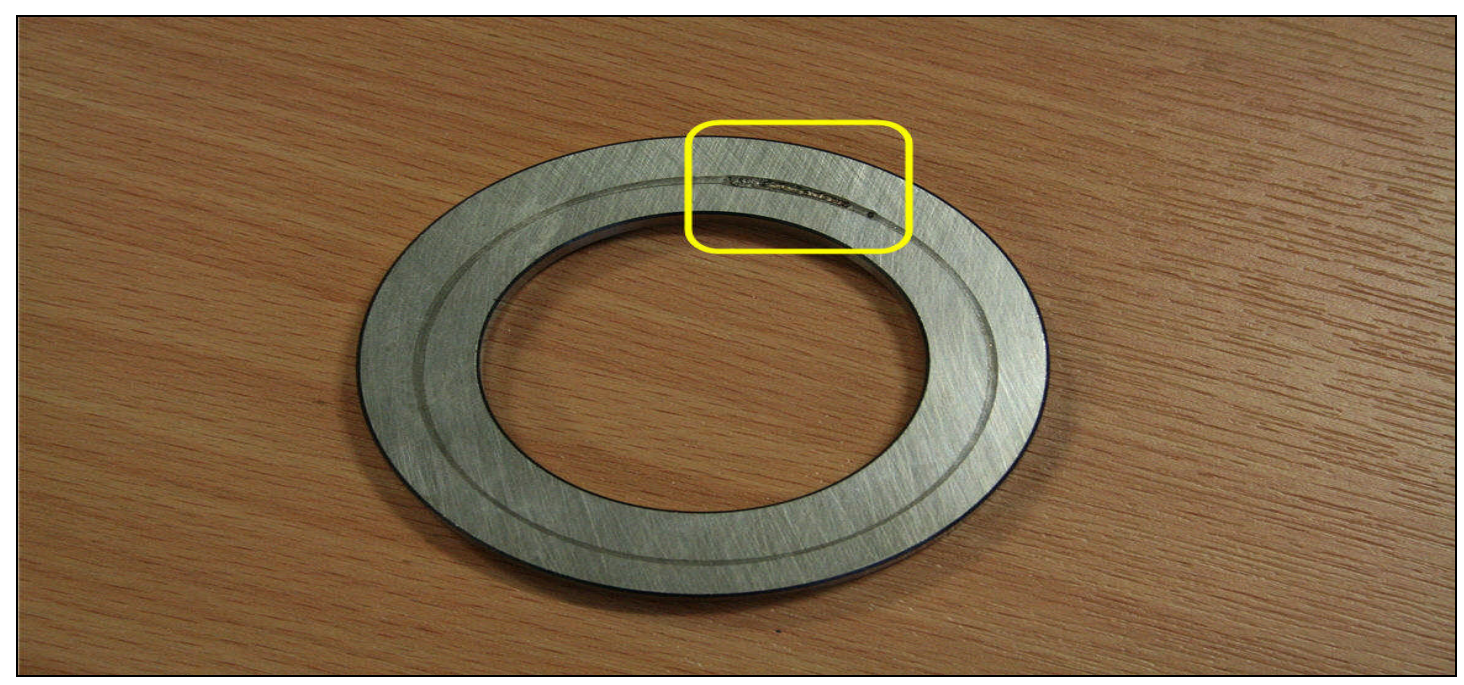

Figure $7 \quad$ Crack zone on flat ring

Thus far the observations have shown $\mathrm{AE}$ can monitor the degradation of an accelerated test; the next phase of analysis involved source identification of $\mathrm{AE}$ activity throughout the test duration. Figures 8 to 10 highlight the trends in source location throughout the test period; the region where the surface damage eventually occurred has been highlighted. Source location estimations employed in the bearing 
test provided another simple and rapid means to correlate AE events measured with a specific fault event on the test bearing.

These figures show that at the start of the test (run-in), figure 8, AE activity was evident within the damaged region with a maximum AE energy value of $249 \times 10^{5}$ atto-Joules $\left(10^{-18}\right)$. At about 10-hrs into operation, the concentration of the AE sources was clearly located at the highlighted region, see figure 9. Lastly at 16-hrs operation the location of the $\mathrm{AE}$ sources was limited to one region where the actual surface damage occurred; estimation of the source location covered a circumferential defect width of approximately $20 \mathrm{~mm}$, see figure 10 . A maximum energy value of $350 \times 10^{5}$ atto-Joules $\left(10^{-18}\right)$ was noted at 16-hrs operation (see figure 10$)$.

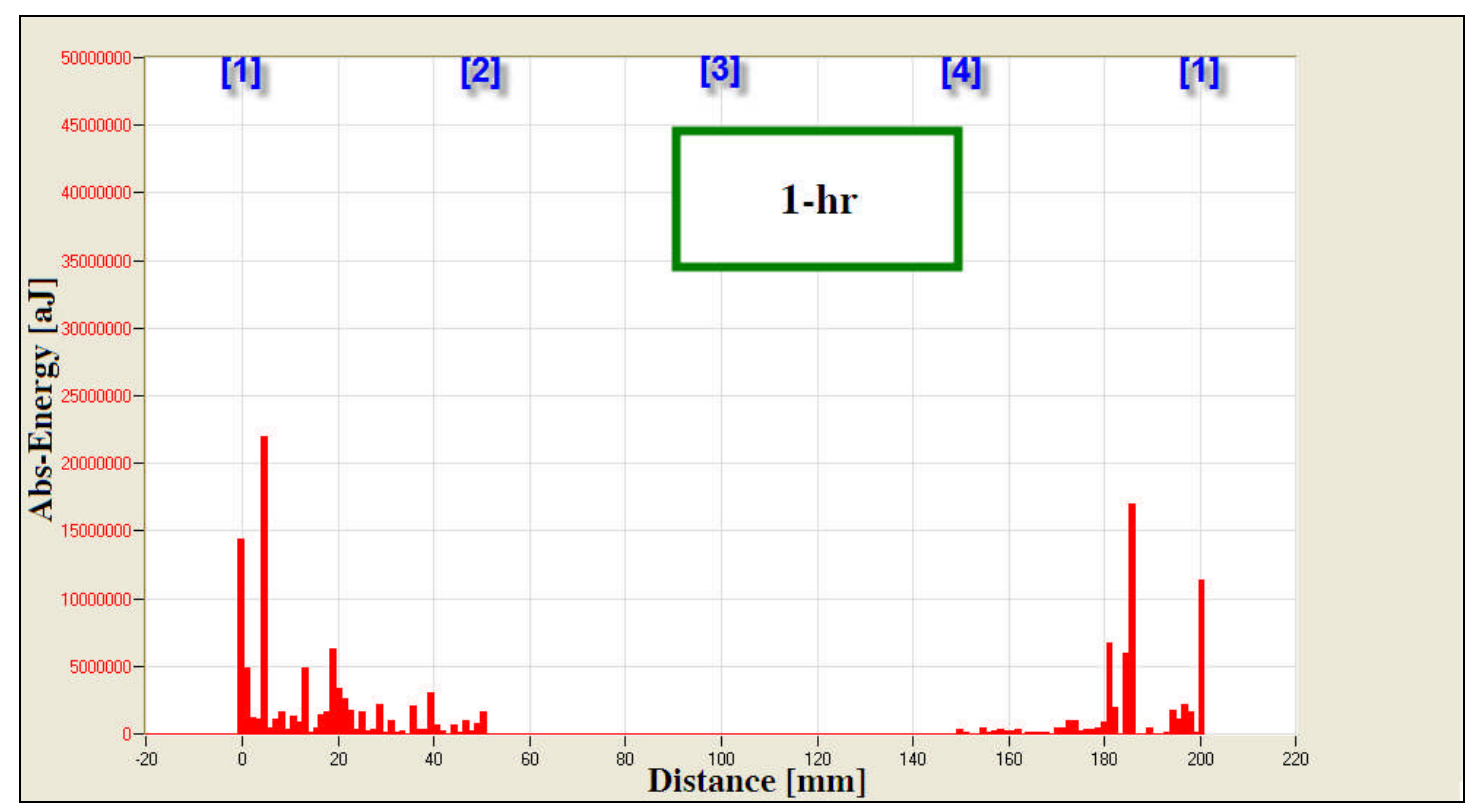

Figure 8 Source location estimates of AE events at 1-hr operation 


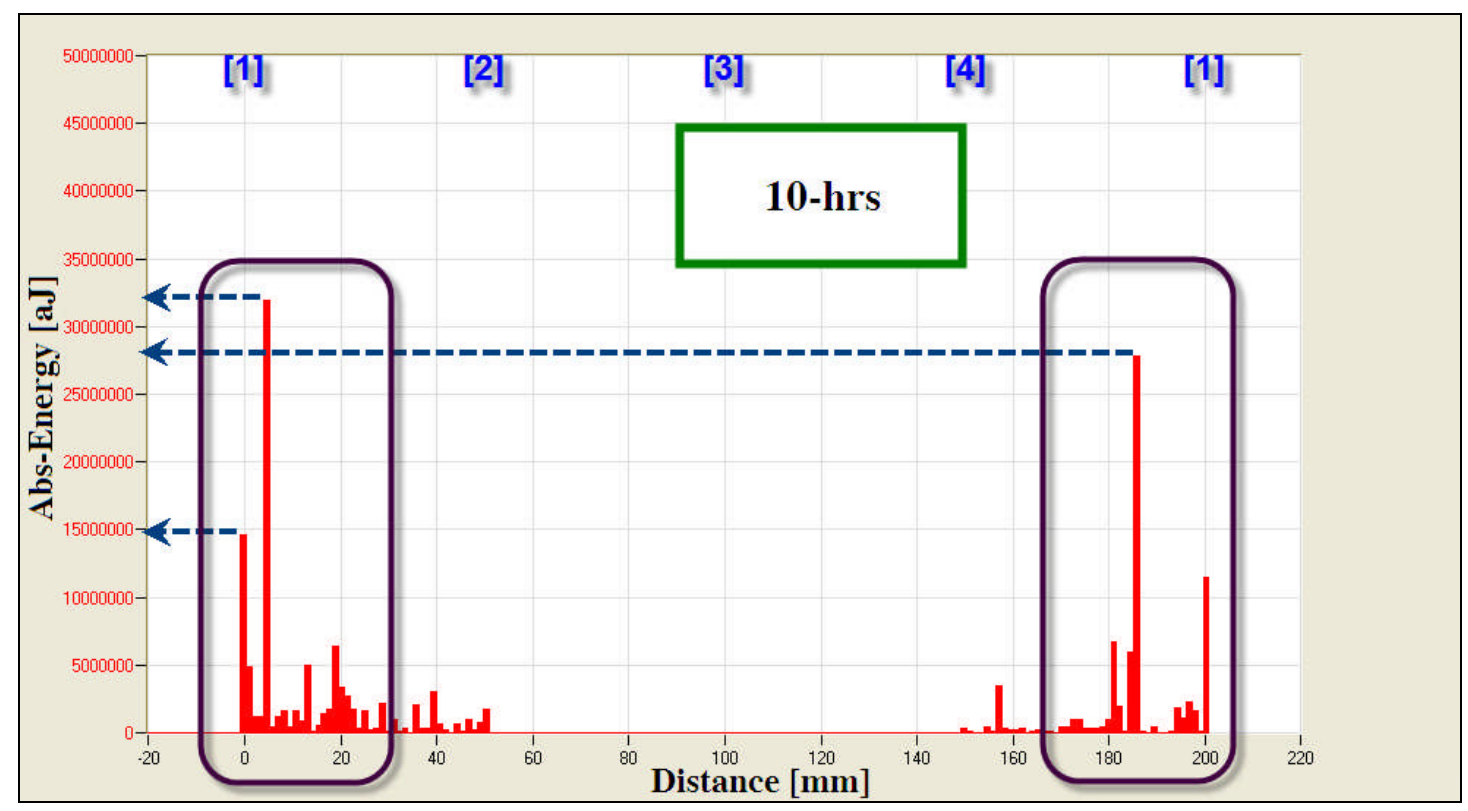

Figure 9 Source location estimates of AE events at 10-hrs operation

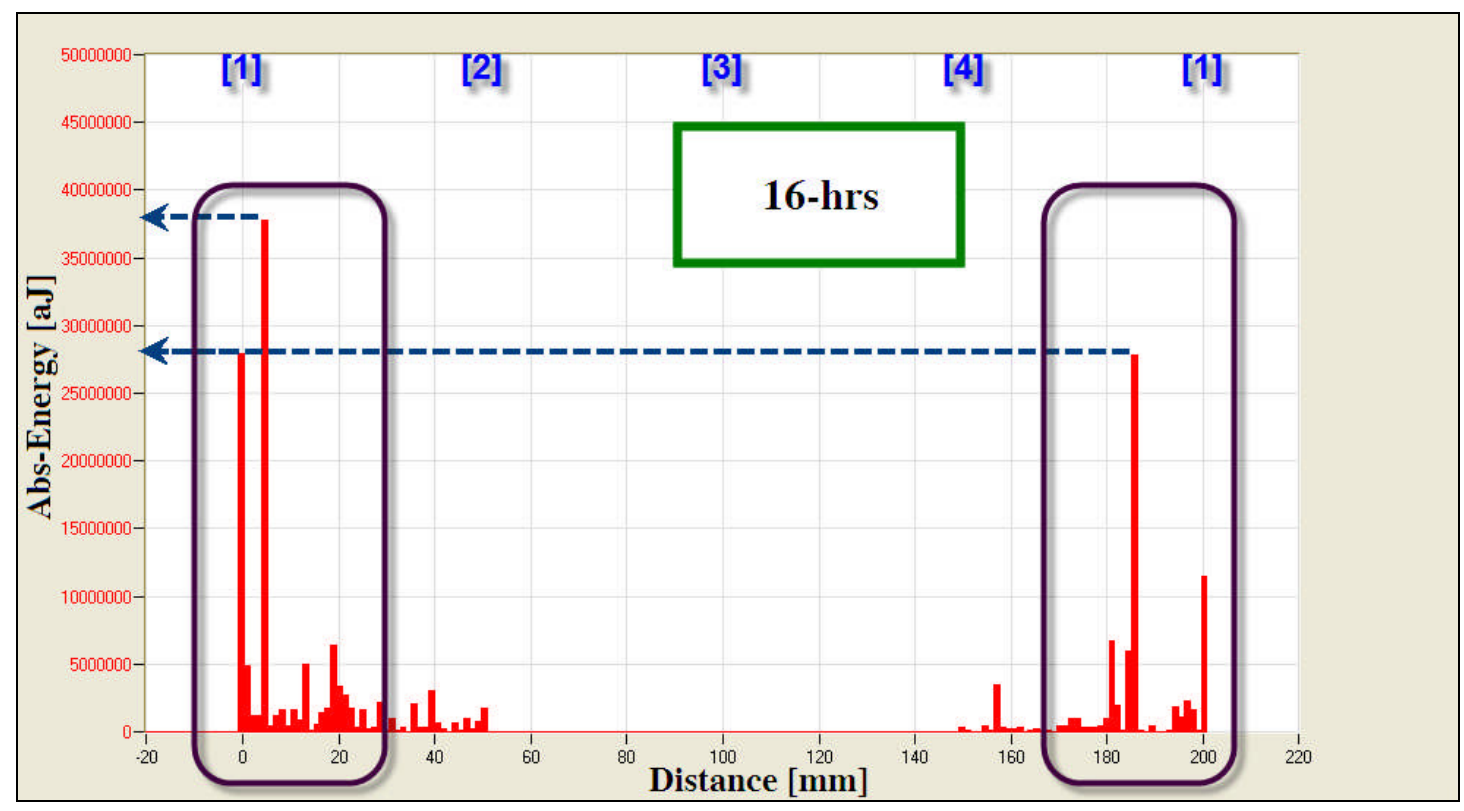

Figure 10 Source location estimates of AE events at 16-hrs operation

\subsubsection{Case II}

The applied load on this test bearing was $35 \mathrm{kN}$. Observations of continuous monitoring of the AE levels for 20-hours of bearing operation are presented in figure 11. It was noted that relatively high levels of AE activity was observed during the first hour of operation; this was attributed to run-in as after this period (1-hr) all measured AE parameters and temperature stabilised. After 14-hrs of operation significant high levels of AE activity was noted, particularly the activity associated with $\mathrm{AE}$ energy. 
At the end of the test, the bearing temperature recorded a maximum value of $37^{\circ} \mathrm{C}$, see figure 11. Also noted on the AE waveform at 14-hrs operation was the high transient nature of the waveform. It is also particularly interesting to note that the waveform observed after 20-hrs of operations showed a periodicity of AE transient bursts at $9 \mathrm{~Hz}$; this periodicity is associated with the defect frequency $(9 \mathrm{~Hz})$ of the bearing and is a clear indication of a damaged bearing, see figure 12. On termination of the test (20-hrs) a visual inspection revealed surface damage at two locations on the race, see figure 13 .

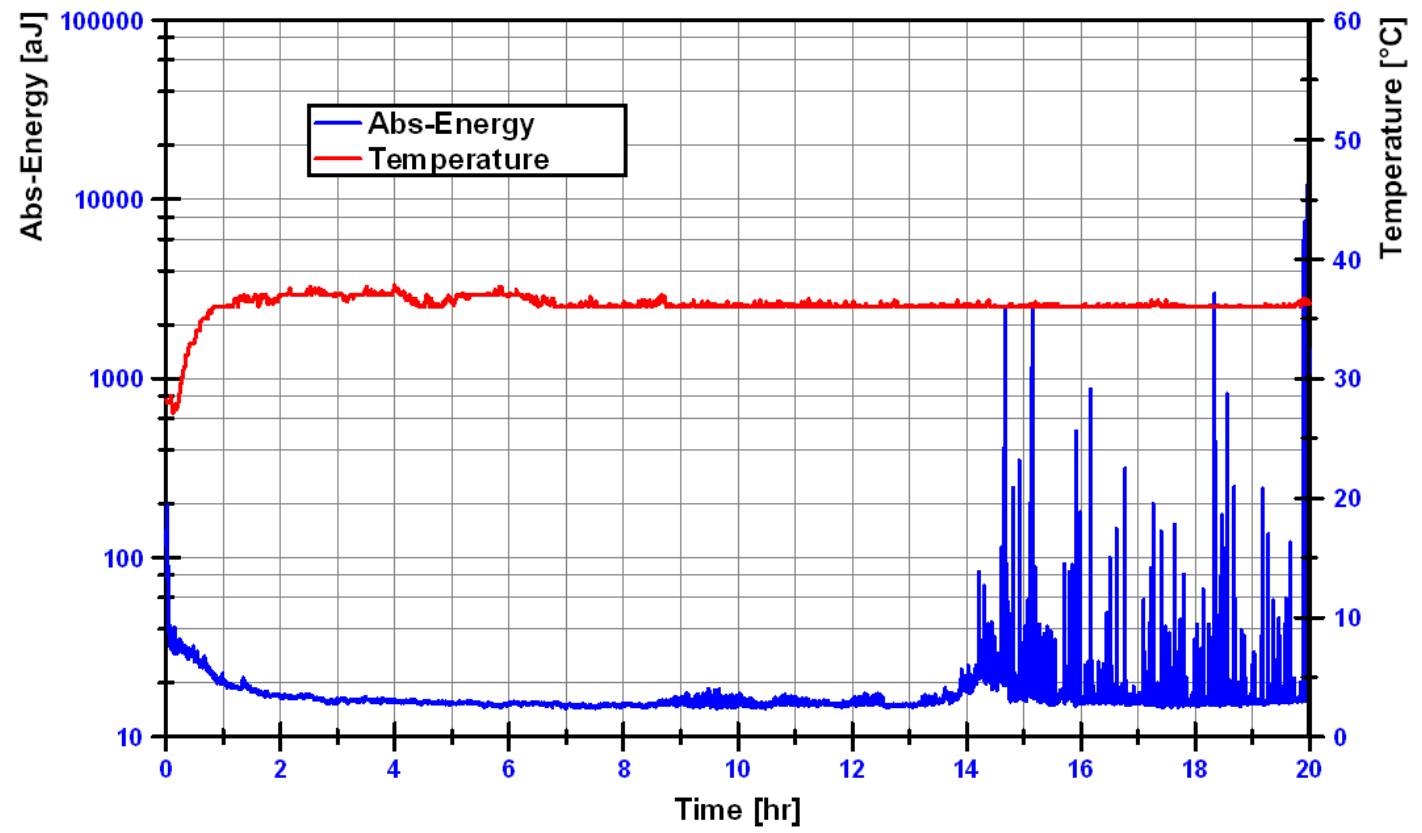

Figure 11 Test conditions run until visually observable surface damage 

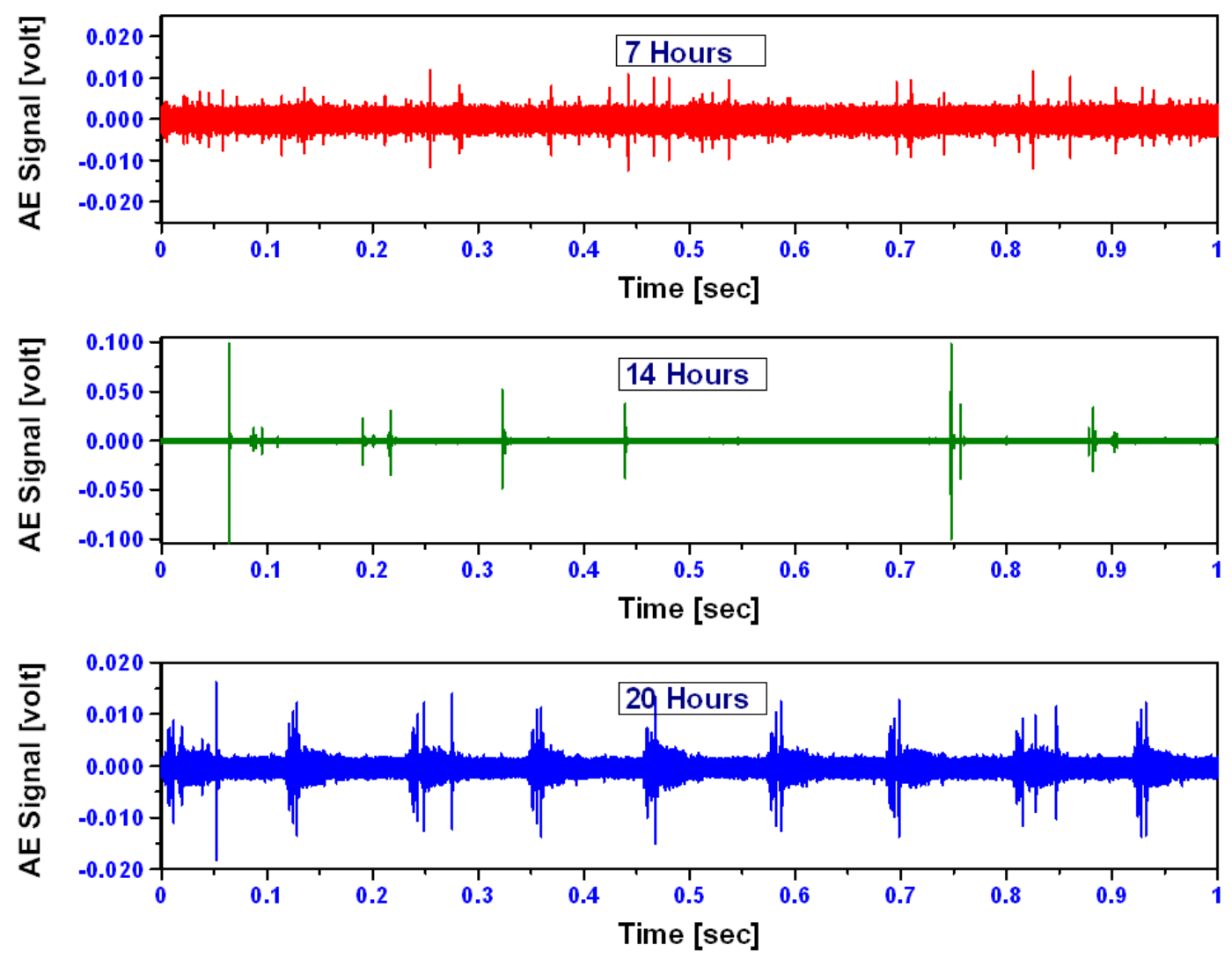

Figure 12 Typical AE waveforms associated with case-II

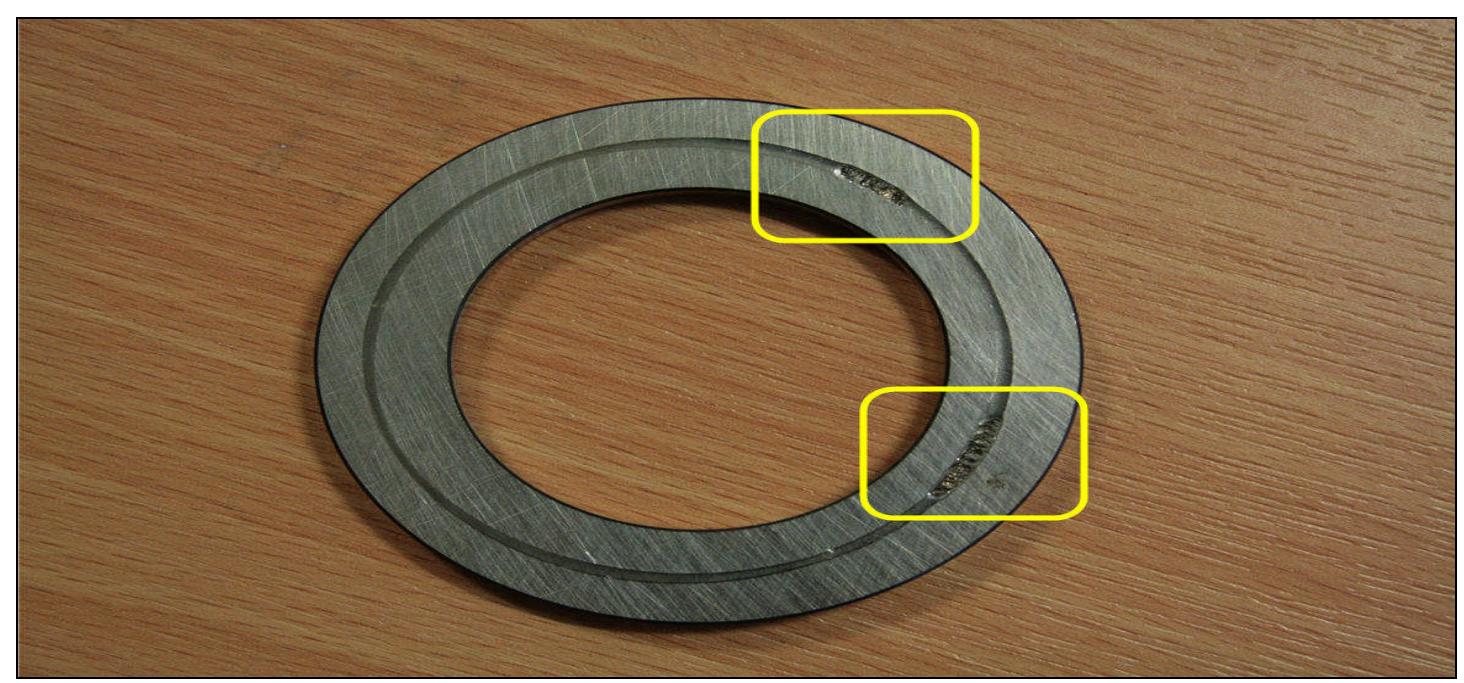

Figure 13 Crack zones on flat ring

As in the previous case the source location over the duration of the test is presented in figures 14 to 16 . At the start of the test, geometric concentrations of AE activity were distributed across the circumferential length of the bearing and this is attributed to the run-in condition, see figure 14. At 14-hrs relatively early signs of concentrated AE source activity of the highlighted zones began to appear, see figure 15; geometric 
concentrations of AE activity in the eventual defect zones became evident with values of $100 \times 10^{3}$ atto-Joules (zone1) and $20 \times 10^{3}$ atto-Joules (zone 2). Figure 16 shows the growing concentration of AE energy from the defect locations; after $20 \mathrm{hrs}$ operation the concentration of the $\mathrm{AE}$ source was clearly located at the two highlighted regions and the maximum energy values of $40 \times 10^{5}$ atto-Joules (zone1) and $42 \times 10^{5}$ atto-Joules (zone 2) were noted. These locations corresponded to the actual defects visually observed at the end of the test, see figure 13.

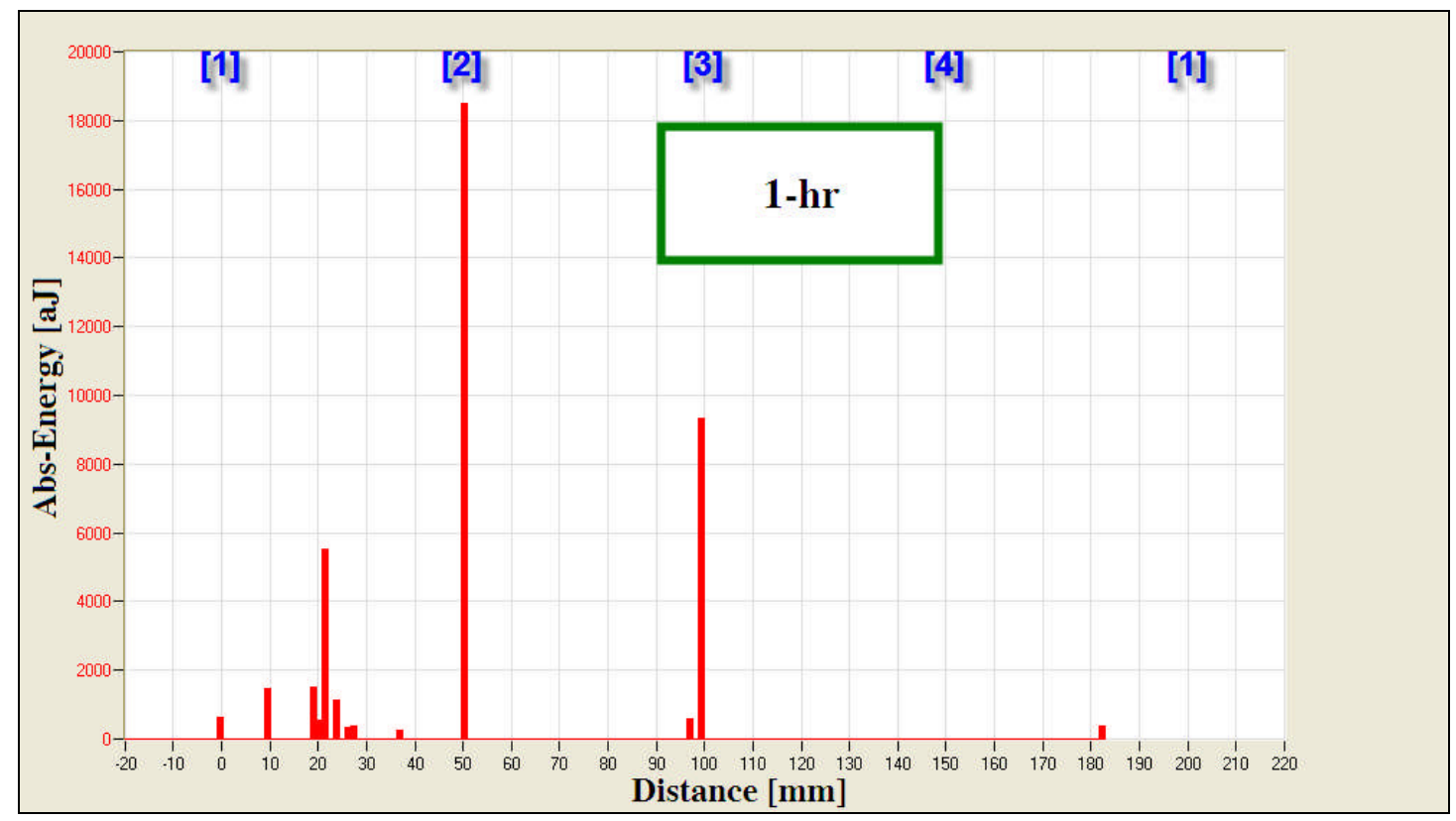

Figure 14 Source location estimates of AE events at 1-hr operation

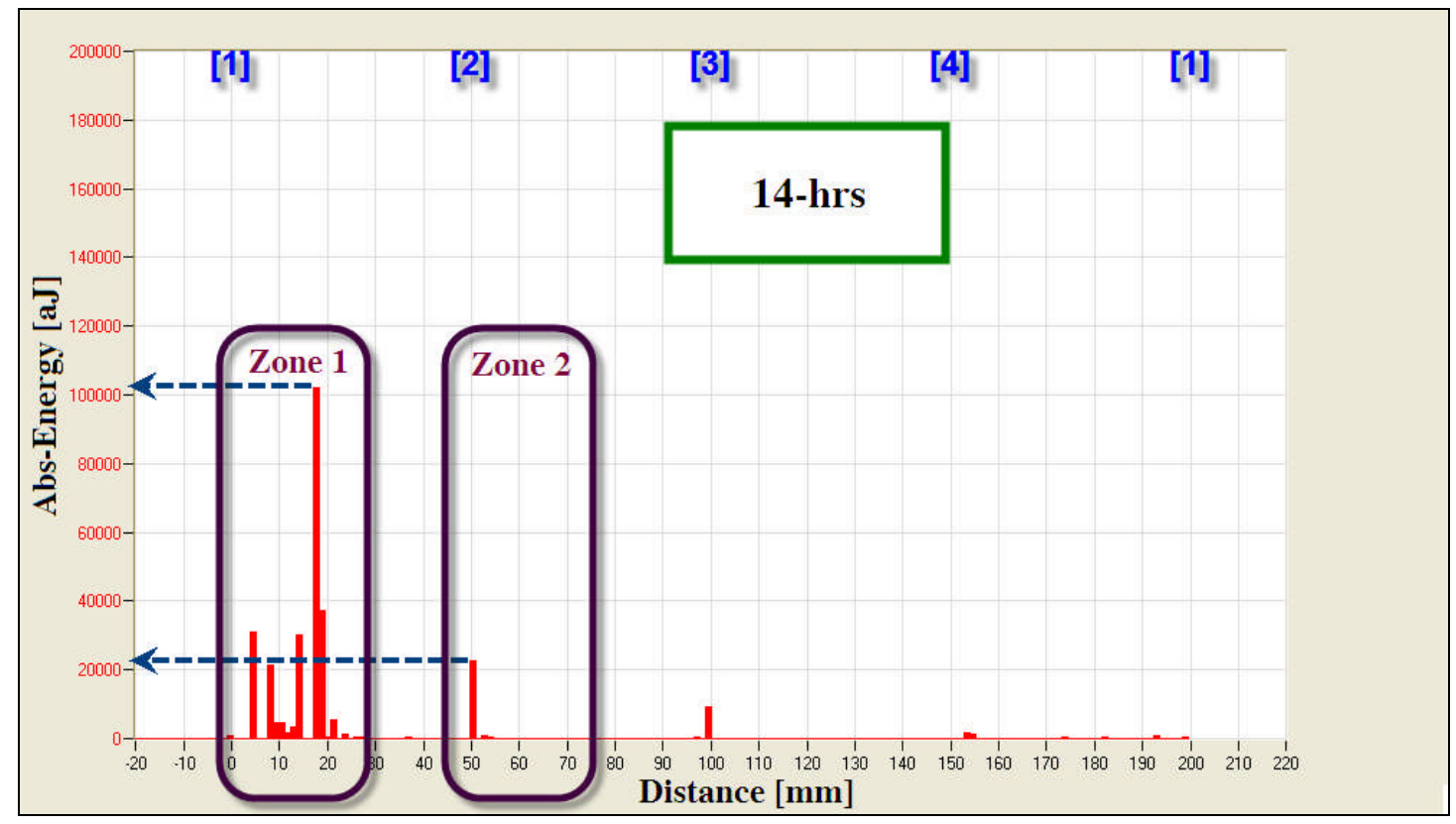

Figure 15 Source location estimates of AE events at 14-hrs operation 


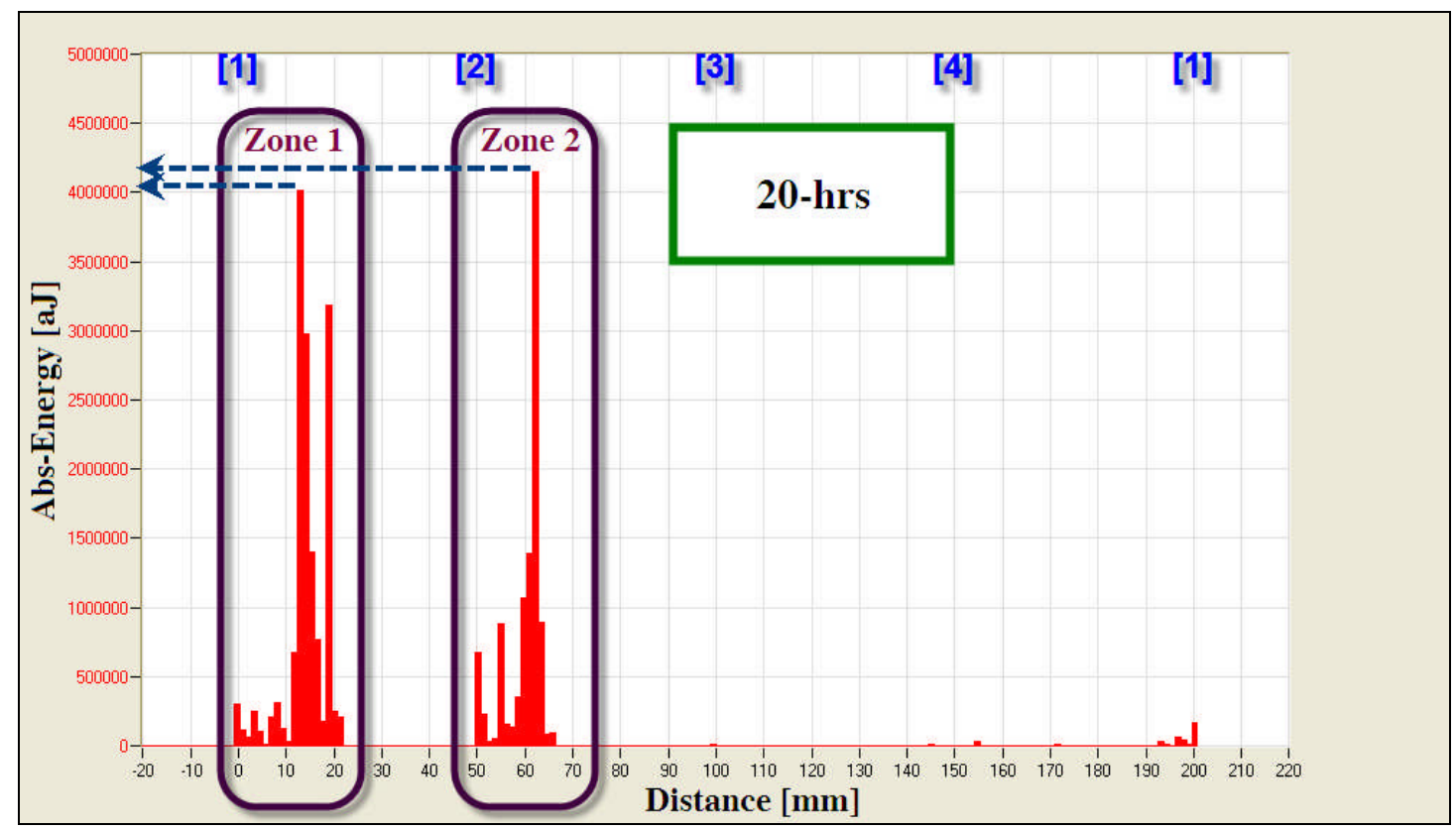

Figure 16 Source location estimates of AE events at 20-hrs operation

\subsubsection{Case III}

This case presents different trends to that noted in the earlier cases. During the start of the test, the relatively high levels of $\mathrm{AE}$ and temperature noted in the previous cases was not observed; observations of continuous monitoring of the AE levels, in addition to bearing temperature, for 50-hrs of bearing operation did not show any considerable rise at (0- to $1-\mathrm{hr})$ of testing. This was attributed to a lower axial load of $20 \mathrm{kN}$ applied on this test bearing, see figure 17. A significant increase in AE levels was noted from 45-hrs of operation until the test was terminated, as shown in figure 17. On the termination of the test, bearing temperature recorded its maximum value of $39^{\circ} \mathrm{C} . \mathrm{AE}$ waveforms recorded after 20-, 45- and 50-hours of testing are presented in figure 18. It clearly shows AE transient events, observed after 45-hours which eventually developed into periodic transient events as the test progressed; the eventual periodicity was $9 \mathrm{~Hz}$ which corresponded to the defect frequency of the bearing. Visual inspection after 50-hrs operation indicated surface damage had occurred in the region, which was located approximately 20mm from ch-2 AE sensor, see figure 19. 


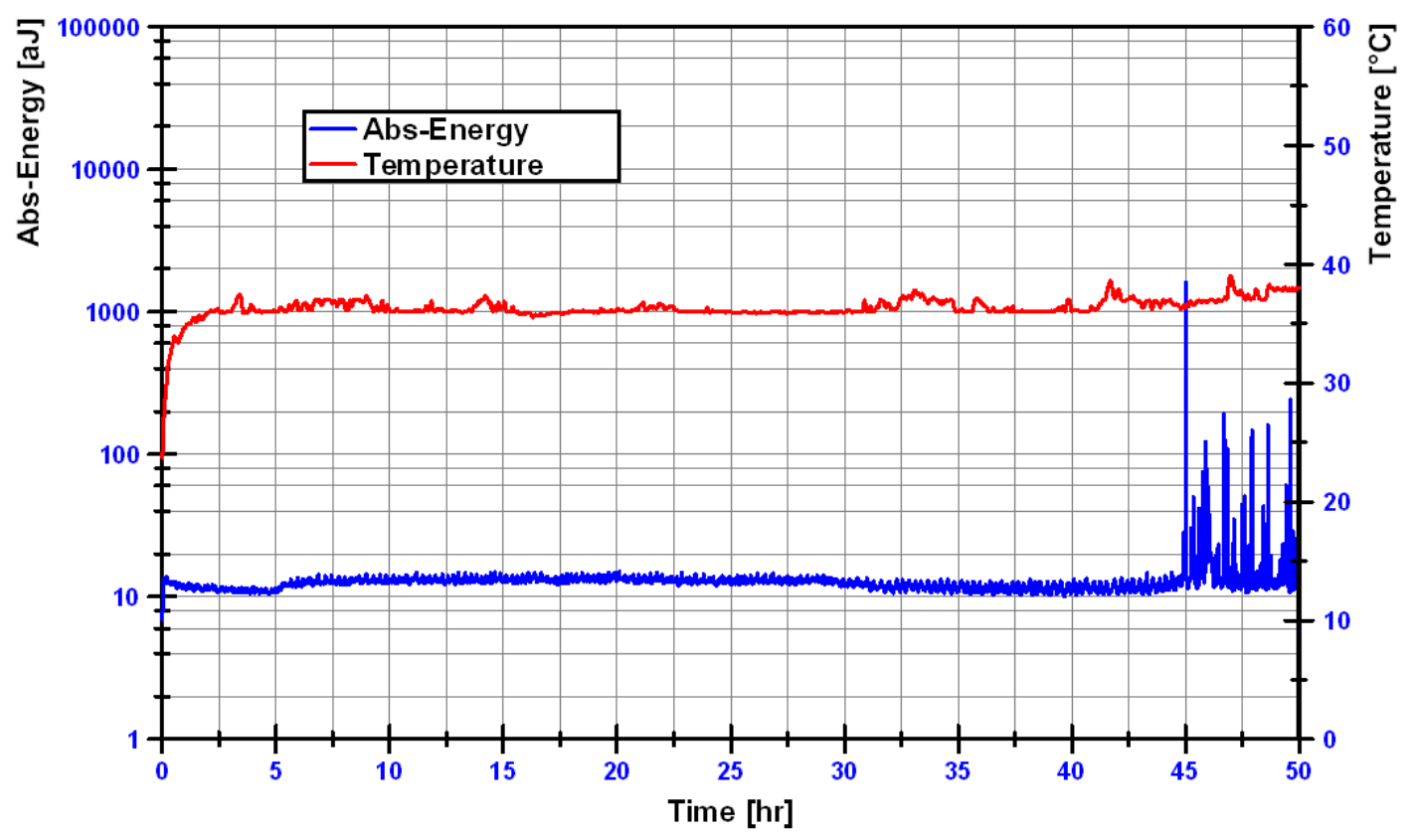

Figure 17 Test conditions run until visually observable surface damage
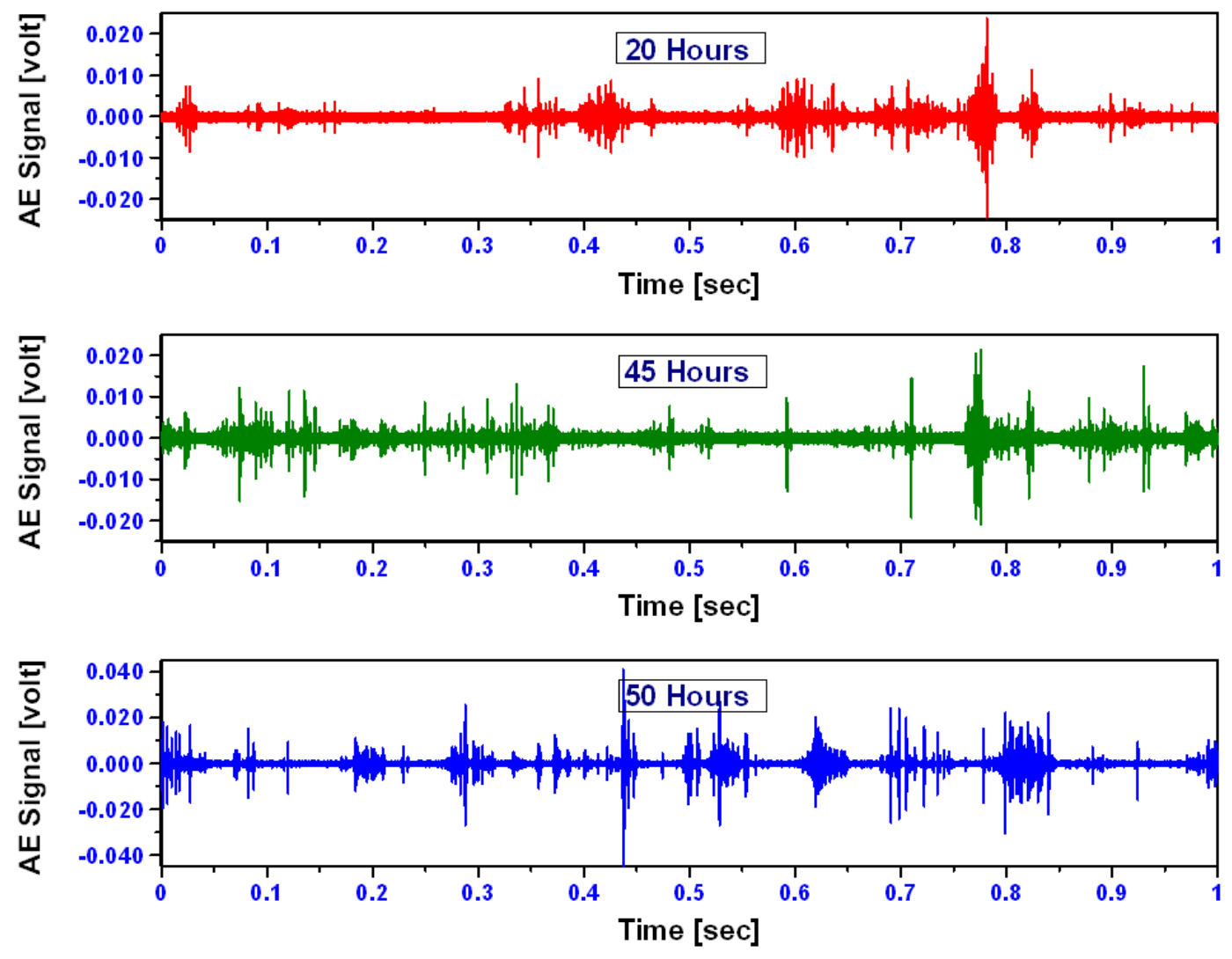

Figure 18 AE waveform 


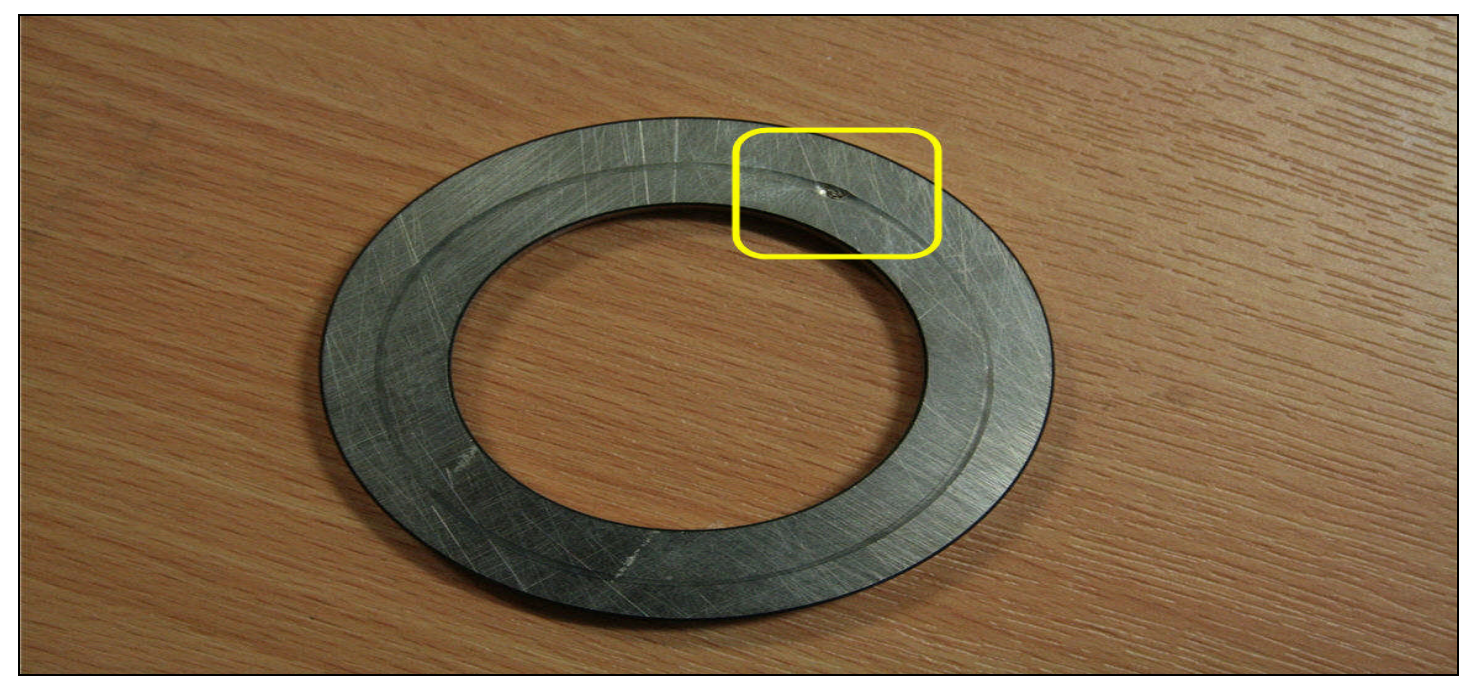

\section{Figure 19 Crack zone on flat ring}

In contrast to the previous cases, a geometric concentration of the AE source was not noted until approximately 40hrs; this is attributed to the low load (20kN) applied on this test; see figure 20. Furthermore, these cumulative plots compute and identify only AE events above the defined threshold $(52 \mathrm{~dB})$. It is particularly interesting to note that the onset of crack development could have been identified as early as 45-hrs into the operation of the test bearing, as shown in figure 21 . From $45 \mathrm{hrs}$ of operation a specific geometric AE source was noted which approximated to a surface damage of $20 \mathrm{~mm}$ in circumferential length in the vicinity of ch-2, see figures 21 and 22.

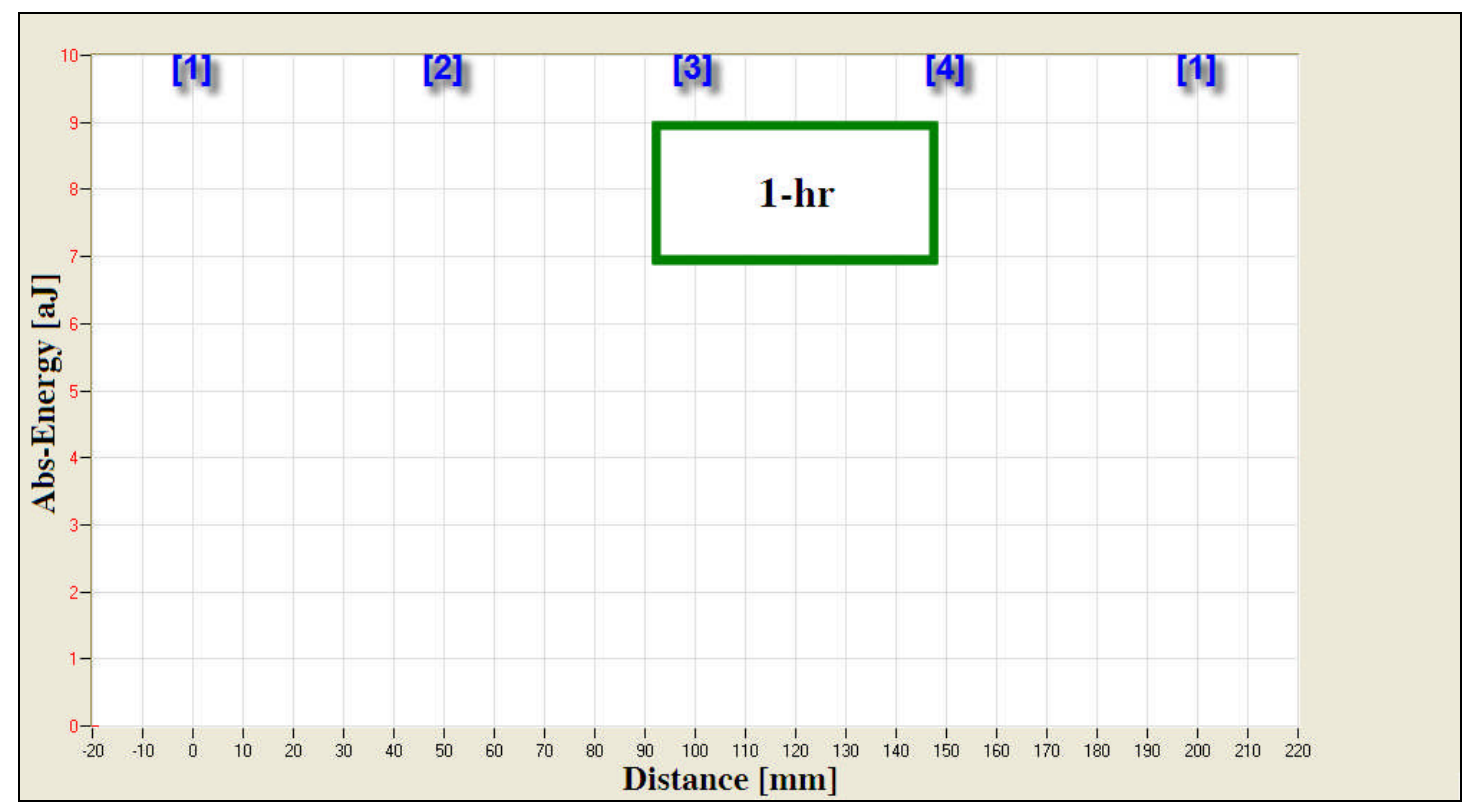

Figure 20 Source location estimates of AE events at 1-hr operation 


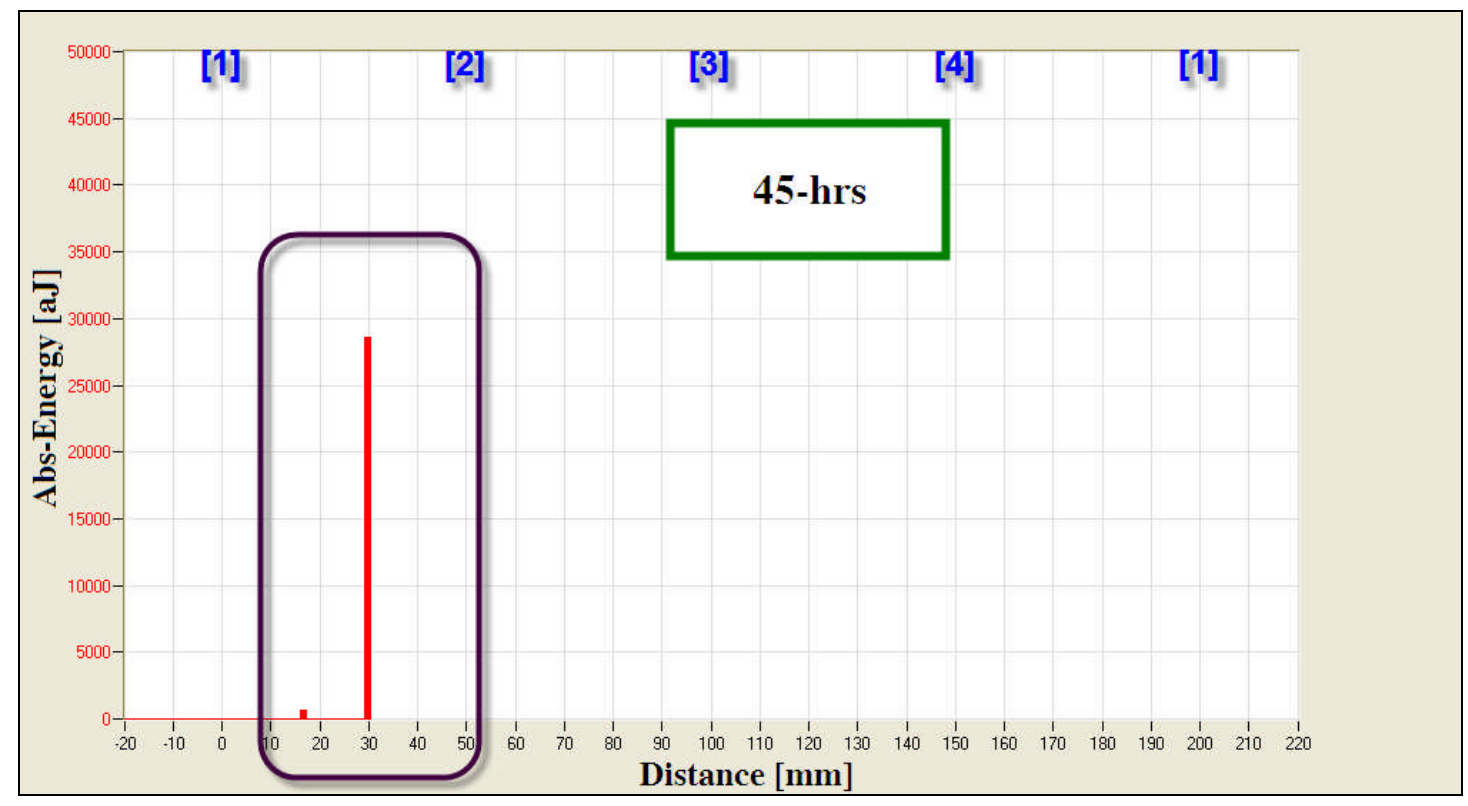

Figure 21 Source location estimates of AE events at 45-hrs operation

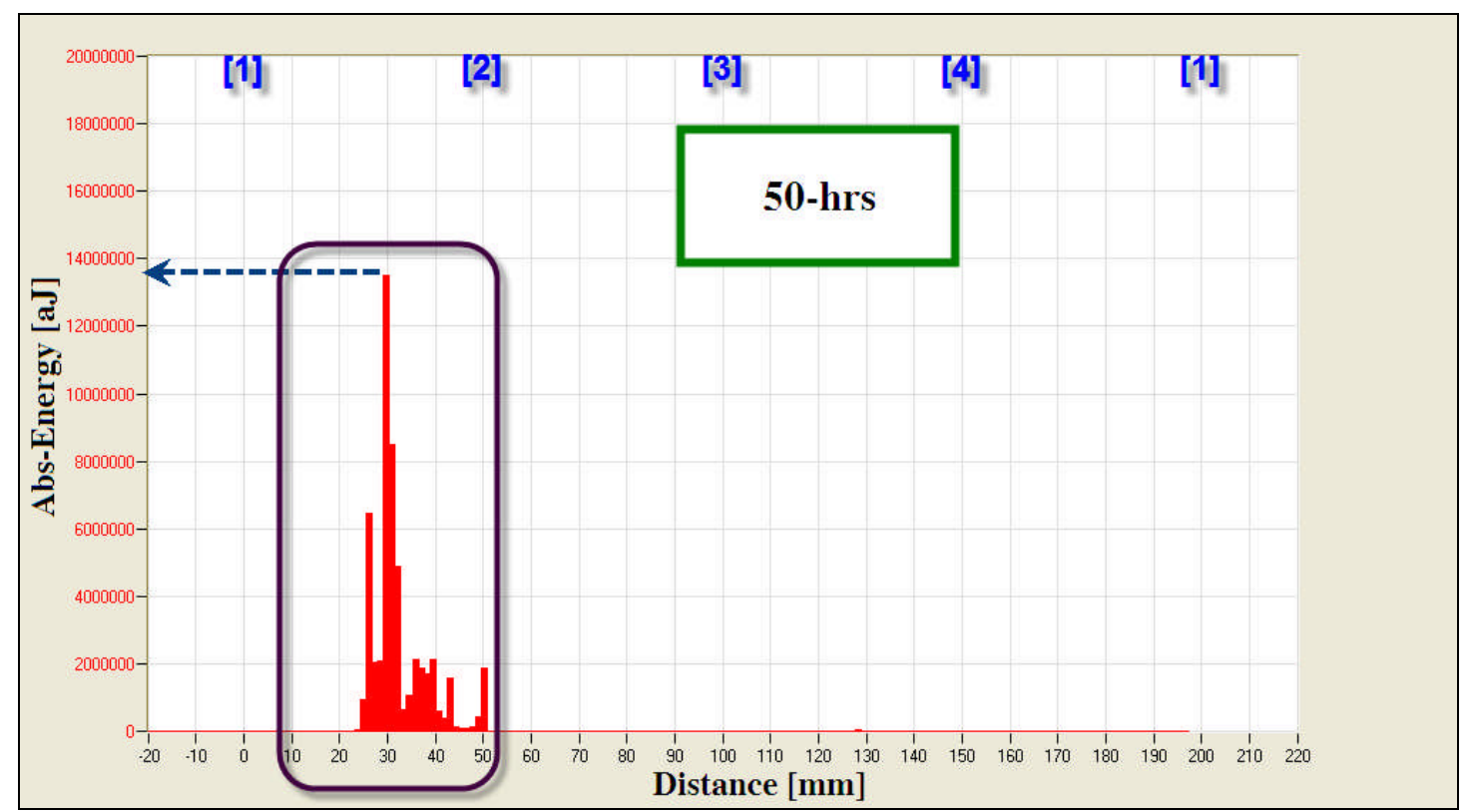

Figure 22 Source location estimates of AE events at 50-hrs operation

\section{Conclusion}

Under natural damage conditions, bearing run-to-failure tests were successfully performed. The study has shown that the AE energy is a reliable, robust and sensitive parameter for detection of incipient cracks and surface spalls in a slow speed bearing whilst in operation. It also successfully demonstrated the ability to determine the 
source of $\mathrm{AE}$ during operation. At the rotational speed on which these tests were employed, this is the first known attempt at correlating $\mathrm{AE}$ and natural defect generation and location.

\section{References}

1 ISO (International Standards Organization Documents) 22096; Condition monitoring and diagnosis of machines - Acoustic Emission. 2008.

2 Mba, D., Rao, Raj B. K. N. Development of Acoustic Emission Technology for Condition Monitoring and Diagnosis of Rotating Machines: Bearings, Pumps, Gearboxes, Engines, and Rotating Structures. The Shock and Vibration Digest 2006 38: 3-16.

3 Jamaludin N.; Mba D.; Bannister R. H., Condition Monitoring of Slow-Speed Rolling Element Bearings Using Stress Waves, Proceedings of the IMECHE Part E Journal of Process Mechanical Engineering, Volume 215, Number 4, 1 November 2001, pp. 245-271(27), Publisher: Professional Engineering Publishing.

4 Morhain, A.; Mba, D., Bearing Defect Diagnosis and Acoustic Emission, Proceedings of the Institution of Mechanical Engineers, Part J: Journal of Engineering Tribology, Volume 217, Number 4 / 2003, Pages: 257 - 272.

5 Miettinen, J., Pataniitty, P. Acoustic Emission in Monitoring Extremely Slowly Rotating Rolling Bearing, Proceedings of 12th International Congress on Condition Monitoring and Diagnostic Engineering Management, COMADEM 99, England.

6 Al-Ghamd and D. Mba, A Comparative Experimental Study on the Use of Acoustic Emission and Vibration Analysis for Bearing Defect Identification And Estimation of Defect Size, Mechanical Systems and Signal Processing 20 (7) (2006), pp. 1537-1571.

7 Choudhury A.; Tandon N., Application of Acoustic Emission Technique for the Detection of Defects in Rolling Element Bearings, Tribology International, Volume 33, Number 1, January 2000, pp. 39-45(7), Publisher, Elsevier Science.

8 Price, E.D.; Lees, A.W.; Friswell, M.I. Detection of Severe Sliding and Pitting Fatigue Wear Regimes Through the use of Broadband Acoustic Emission, 
IMechE Journal of Engineering Tribology, Volume 219, Number 2, April 2005, pp. 85-98.

9 Yoshioka, T. Detection of rolling contact subsurface fatigue cracks using acoustic emission technique, Journal of the Society of Tribologists and Lubrication Engineers, Volume 49, June 1992.

10 M. Elforjani, D. Mba, Observations and location of Acoustic Emissions for a naturally degrading rolling element thrust bearing, Journal of Failure Analysis and Prevention, Publisher, Springer Boston, ISSN: 1547-7029 (Print) 18641245 (Online), May 2008.

11 Harris, Tedric A., Rolling Bearing Analysis, $4^{\text {th }}$ edition, 2001, John Wiley \& Sons, Inc., New York, USA.

12 Palmgren, A., Ball and Roller Bearing Engineering, $3^{\text {rd }}$ edition, 1959, SKF Industries, S. H. Burbank \& CO., INC., Philadelphia, USA. 